\title{
Avaliação da aprendizagem de estudantes com deficiência na educação superior*
}

\author{
Tania Mara Zancanaro Pieczkowski ${ }^{\mathrm{I} \text { II }}$ \\ http://dx.doi.org/10.1590/S2176-6681/269030614
}
* O texto, originalmente, está publicado em uma das edições da Associação Nacional de Pós-Graduação e Pesquisa em Educação (Anped). Porém, foi reestruturado para esta versão.
Universidade Comunitária da Região de Chapecó (Unochapecó), Chapecó, Santa Catarina, Brasil. E-mail: $<$ taniazp@unochapeco.edu. br >; <http://orcid.org/0000- 0002-5257-7747>.
II Doutora em Educação pela Universidade Federal de Santa Maria (UFSM), Santa Maria, Rio Grande do Sul, Brasil.

\section{Resumo}

Aborda a avaliação de estudantes com deficiência no contexto da educação superior na perspectiva da educação inclusiva e evidencia as inquietações docentes diante desse desafio. Parte da concepção da avaliação como um processo multifacetado e destaca alguns de seus aspectos, como a aprendizagem discente. O texto está inspirado em um excerto da tese de doutorado da autora, cujo objetivo foi tensionar a inclusão de estudantes com deficiência na educação superior e compreender os efeitos desse processo na docência universitária. O material empírico, gerado por meio de entrevistas narrativas realizadas com professores que atuam junto a estudantes com deficiência em diferentes cursos de graduação, em duas universidades de Santa Catarina, foi examinado sob a perspectiva da análise do discurso, amparada em referenciais foucaultianos. O estudo aponta que a presença de estudantes com deficiência na docência universitária potencializa os conflitos inerentes à prática avaliativa da aprendizagem, caracterizada, predominantemente, como classificatória e seletiva, enquanto os movimentos da inclusão produzem subjetividades solidárias. No encontro com estudantes com deficiência, os professores descobrem a pluralidade 
da inclusão, passando a compreendê-la como um desafio que provoca desassossegos, mas também a desconstrução de olhares padronizados e a compreensão de que, para ensinar e avaliar, é preciso aprender com a diferença.

Palavras-chave: inclusão na educação superior; estudantes com deficiência; docência universitária.

\section{Abstract \\ Learning assessment of disabled undergraduate students}

This article approaches the disabled undergraduate students' assessment in the perspective of inclusive education and highlights the concerns of professors faced by these challenges. It starts with the conception of assessment as a multifaceted process, bringing up some of its aspects such as student learning. The text is based on an excerpt of my doctorate thesis, which aimed at discussing the inclusion of disabled students in undergraduation and to understand the effects of this process in college teaching. Empirical data - produced by means of narrative interviews with professors working with disabled students in different undergraduate courses of two universities of Santa Catarina - was examined under the perspective of discourse analysis, supported by Foucauldian references. The study shows that the presence of disabled students in college enhances the conflicts inherent to the learning assessment, predominantly characterized as qualifying and selective, while inclusion movements produce solidary subjectivities. In contact with disabled students, professors discover the plurality of inclusion, and understand it as an unrest that brings up challenges, as well as the deconstruction of standardized views and the understanding that, in order to teach and evaluate students, it is necessary to learn from the differences.

Keywords: undergraduate inclusion; disabled students; college teaching.

\section{Introdução}

Os estudos empreendidos acerca da temática da avaliação, longe de estarem esgotados, abrem novas perspectivas, considerando os movimentos vivenciados nos cenários do ensino e da aprendizagem e as dúvidas e vulnerabilidades que acompanham a prática avaliativa.

Os desafios da docência universitária são intensos e potencializados diante das demandas criadas pela inclusão de estudantes com deficiência, 
somadas à frágil identidade profissional, aspectos salientados por Isaia e Bolzan (2009). As autoras afirmam que os professores normalmente assumem a docência a partir do conhecimento específico de suas áreas de formação ou atuação, "centrando-se mais em suas especialidades, desconsiderando a função docente que está claramente vinculada ao compromisso formativo da educação superior" (Isaia; Bolzan, 2009, p. 168).

Ao exercer a docência com "o diferente", abre-se uma possibilidade para que profissionais de distintas áreas do conhecimento, atuantes na educação superior, descubram que, mesmo que dominem o conteúdo específico e acumulem títulos acadêmicos, isso não basta, pois a docência é outra profissão, é o encontro com o novo, com o imprevisível.

Dentre as atribuições docentes está a de avaliar os estudantes. Luckesi (2011) alerta para equívocos nas práticas pedagógicas avaliativas, que predominantemente se constituem mais de provas e exames e classificações em termos de aprovação/reprovação, de categorização e de seleção do que propriamente de avaliação. Luckesi (2011, p. 2015) define a avaliação da aprendizagem

[...] como um ato amoroso, no sentido de que a avaliação, por si, é um ato acolhedor, integrativo, inclusivo. [...] A avaliação tem por base acolher uma situação, para, então (e só então), ajuizar a sua qualidade, tendo em vista dar-lhe suporte de mudança, se necessário. A avaliação, como ato diagnóstico, tem por objetivo a inclusão e não a exclusão.

Este texto está ancorado em um excerto de tese de doutorado em educação que aborda os efeitos da presença de estudantes com deficiência - incluídos na educação superior - na docência universitária. O estudo evidencia o cenário de expansão da educação superior brasileira nos últimos anos e, vinculado a esse fato, o aumento do ingresso de estudantes com deficiência nesse nível de ensino.

Para a pesquisa que resultou na tese, foram entrevistados dez professores atuantes com alunos com deficiência em diferentes cursos de graduação, em duas universidades de Santa Catarina, identificadas como A (pública federal) e B (comunitária). A tese desenvolvida é de que a presença de estudantes com deficiência produz efeitos na docência universitária, implicando a forma de ser docente, ou seja, as práticas pedagógicas e a maneira de conceber a docência.

O material empírico gerado por meio de entrevistas narrativas foi examinado sob a perspectiva da análise do discurso, amparada em referenciais foucaultianos, nos quais a análise não tem como escopo trabalhar com a língua como um sistema abstrato, mas com seu papel na produção de sentidos ou efeitos. "Trata-se de analisar porque aquilo é dito, daquela forma, em determinado tempo e contexto, interrogando sobre as 'condições de existência' do discurso" (Sales, 2012, p. 125).

Ao examinarmos discursos, devemos estar atentos, pois estes podem "[...] admitir um jogo complexo e instável em que o discurso pode ser, ao mesmo tempo, instrumento e efeito de poder, e também obstáculo, 
escora, ponto de resistência e ponto de partida de uma estratégia oposta" (Foucault, 2005, p. 96).

Um dos agrupamentos temáticos analisados na tese de doutorado discute a avaliação de estudantes com deficiência na educação superior e foi ponto de partida para a elaboração deste texto, redimensionado para esta versão. Em consonância com a perspectiva foucaultiana, não há a pretensão de tecer juízos de valor ou apontar o caminho verdadeiro, mas de evidenciar os efeitos de verdade criados pelos discursos da inclusão, o que resulta em subjetivação docente.

\section{Inclusão de estudantes com deficiência na educação superior}

A expansão do número de instituições, cursos e vagas no Brasil, nos últimos anos, contribuiu para o aumento das matrículas na educação superior de estudantes com deficiência. De acordo com o Censo da Educação Superior 2013 (Brasil. Inep, 2015), observa-se um crescimento significativo de 590,78\% no número de estudantes com deficiência matriculados na educação superior em dez anos: em 2003 eram 5.078, em 2011 eram 23.250 e em 2013, 29.034.

No entanto, esses números, comparados ao total de estudantes matriculados no ensino superior - 7,3 milhões -, representam um percentual baixo, de apenas $0,41 \%$ do total de matrículas, especialmente se tomarmos como parâmetro o número de pessoas com deficiência no Brasil, que, conforme o Censo Demográfico 2010, é de 45.606.048. Esses registros divulgados pelo Instituto Brasileiro de Geografia e Estatística (IBGE) apontam que o número de pessoas que declararam ter pelo menos uma das deficiências investigadas corresponde a $23,9 \%$ da população brasileira (IBGE, 2012).

Vale destacar que, conforme define o Decreto $n^{\circ}$ 6.949/2009, que promulga a Convenção Internacional sobre os Direitos das Pessoas com Deficiência e seu Protocolo Facultativo, assinados em Nova York, em 30 de março de 2007, art. $1^{\circ}$, pessoas com deficiência

[...] são aquelas que têm impedimentos de longo prazo de natureza física, mental, intelectual ou sensorial, os quais, em interação com diversas barreiras, podem obstruir sua participação plena e efetiva na sociedade em igualdades de condições com as demais pessoas. (Brasil, 2009).

Nessa perspectiva, o foco da deficiência não é o sujeito, individualmente. Há uma interdependência com o contexto mais amplo. É nesse cenário que a acessibilidade para estudantes com deficiência na educação superior ganha destaque, pois, em muitas situações, é condição para a aprendizagem. A acessibilidade é compreendida como

[...] possibilidade e condição de alcance para utilização, com segurança e autonomia, de espaços, mobiliários, equipamentos urbanos, edificações, transportes, informação e comunicação, inclusive seus sistemas e tecnologias [...]. (Brasil, 2015, art. $2^{\circ}$ ). 
A presença de estudantes com deficiência cria novas demandas nas universidades, como: o cuidado para não penalizá-los pela falta de adequação institucional; a superação de concepções padronizadoras de desenvolvimento e aprendizagem; o fortalecimento do princípio do reconhecimento da diferença; a superação de barreiras arquitetônicas, atitudinais e de comunicação, entre outras.

\section{Avaliação da aprendizagem de estudantes com deficiência: perspectivas docentes}

O Quadro 1 sintetiza informações relativas aos docentes que participaram do estudo por meio de entrevistas narrativas. As informações que seguem visam situar o leitor acerca do contexto das materialidades empíricas. Trata-se de professores com caminhadas na docência entre dois anos e meio e 25 anos, com formação acadêmica em diferentes áreas do conhecimento e atuantes em vários cursos de graduação. Embora cada participante da pesquisa seja identificado como "docente", seguido do número que representa a ordem sequencial crescente do nosso encontro, foram entrevistados professores de ambos os sexos. Optei por generalizar, sem diferenciação de gênero em cada intervenção, para simplificar a escrita. A definição dos participantes ocorreu junto aos setores institucionais que registram a presença de estudantes com deficiência nas duas universidades. Cinco docentes estavam vinculados à universidade pública federal (identificada como instituição de educação superior - IES - A) e cinco à universidade comunitária (identificada como IES B), definidos mediante convite, seguindo a ordem sequencial das indicações institucionais.

O Quadro 1 indica o conjunto dos dez participantes do estudo original. Porém, ao longo deste texto são apresentados fragmentos das narrativas de sete docentes, representativas das manifestações gerais, especificamente no que se refere à avaliação da aprendizagem de estudantes com deficiência na educação superior, ilustrando, dessa forma, o recorte proposto.

Apresentados os sujeitos da pesquisa, ressalto minha percepção de que a avaliação é um tema polêmico, e falar da avaliação na educação especial é ainda mais desafiador. A escola moderna funcionou (e funciona) como uma eficaz estratégia de disciplinamento e controle, ideia salientada por Foucault, especialmente na obra Vigiar e punir. Embora as tendências atuais sejam para estruturar os ambientes de aprendizagem e as metodologias de forma que a colaboração, a resolução de problemas, o trabalho em redes e o protagonismo estudantil ganhem espaço, ainda são muito presentes as tecnologias individualizantes, que segundo Gallo (2004) nos parecem naturais, mas são recentes. Ao transpor essa ideia para o contexto escolar, percebe-se que um recurso simples e eficaz para disciplinar e exercer o poder controlador está na disposição das classes em filas. 


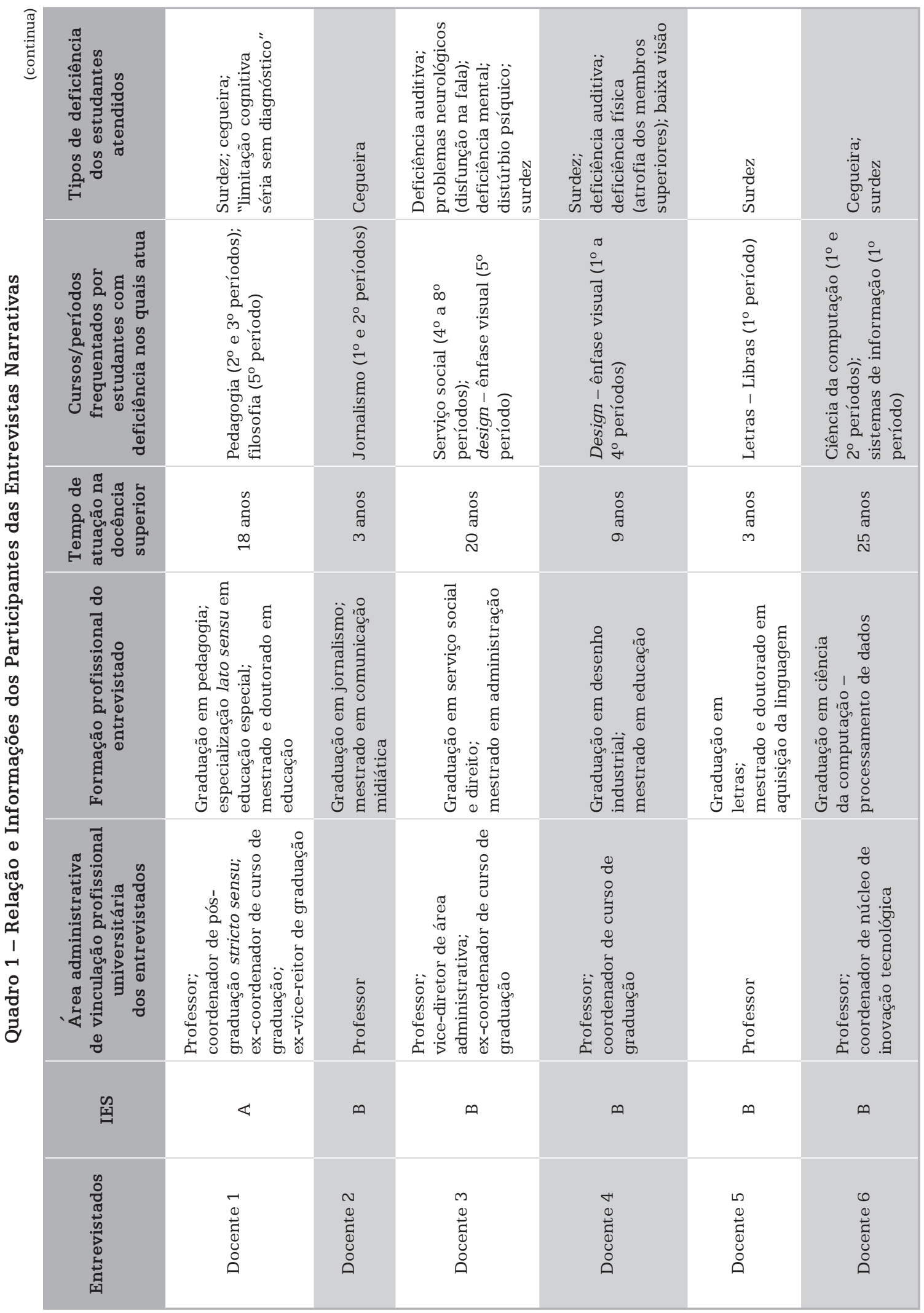




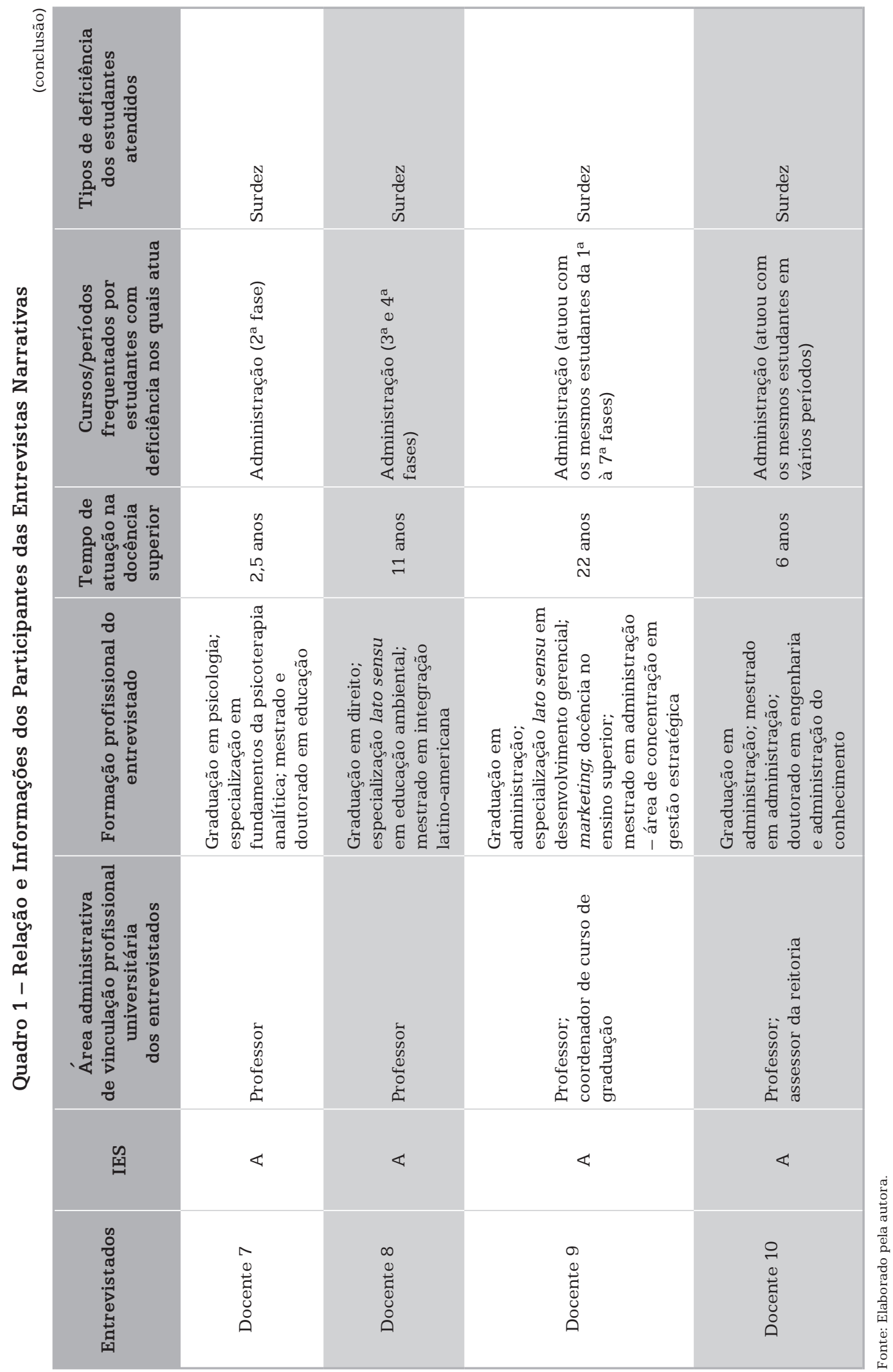


Essa disposição permite que todos os alunos sejam vigiados e controlados constantemente por um único professor. Tais tecnologias atingem os indivíduos em seus próprios corpos e comportamentos, constituindose numa verdadeira "anatomia política", que individualiza a relação de poder. Essas estratégias de dominação, através da delimitação de espaços e da disciplina corporal, diferem quase nada em sua aplicação, seja nos exércitos, seja nas escolas. (Gallo, 2004, p. 92).

Segundo Gallo, para que a educação pudesse cientificizar-se com a pedagogia, era necessário mais do que controlar os alunos,

[...] também era necessário poder quantificá-los em seu processo de aprendizagem, para ordená-los através da máthêsis e da taxinomia. Uma das táticas instrumentais mais eficazes foi fornecida exatamente através da tecnologia do exame (Gallo, 2004, p. 92).

Para Foucault (2007, p. 102), "[...] máthêsis é a ciência das igualdades, portanto, das atribuições e dos juízos; é a ciência da verdade; já a taxinomia trata das identidades e das diferenças; é a ciência das articulações e das classes; é o saber dos seres".

Foucault descreve as tecnologias de disciplinamento, vigilância, normalização e controle, utilizadas pelas instituições modernas, especialmente no século 18, que resultam, dentre outras manifestações, na quantificação dos estudantes, o que vivenciamos também nos dias atuais.

E pelo jogo dessa quantificação, dessa circulação dos adiantamentos e das dívidas, graças aos cálculos permanentes das notas a mais ou a menos, os aparelhos disciplinares hierarquizam, numa relação mútua, os "bons" e os "maus" indivíduos (Foucault, 1999, p. 151).

O autor prossegue afirmando que as classificações têm um duplo papel: "[...] marcar os desvios, hierarquizar as qualidades, as competências e as aptidões; mas também castigar e recompensar" (Foucault, 1999, p. 151).

Assim, o exame se constitui em uma estratégia de controle e vigilância, de acesso à intimidade do estudante, tanto no aspecto pedagógico quanto no aspecto político.

[...] este instrumento declarado de poder, acaba por constituir-se na tecnologia mesma da transmissão do saber, pois é através do exame que o processo de ensino-aprendizagem é verificado, controlado, planejado e re-planejado etc. (Gallo, 2004, p. 93).

\section{Nesse sentido,}

O nascimento da pedagogia como "ciência da educação" deveu-se, pois, ao advento da tecnologia dos exames, tornando possível a metrificação, a quantificação da aprendizagem, colocando sua organização no âmbito da prévia organização estratégica. O professor, assim, além de ser aquele que tem o poder de transmitir conhecimentos, dado seu saber acumulado, é também aquele que tem o poder de cobrar dos alunos o conhecimento que lhes foi transmitido, tornando o seu poder muito mais "visível", muito mais palpável, e menos abstrato, pois sua é também a mão que pune, através do castigo físico ou simplesmente através da nota e das complicações na vida acadêmica, no caso de o aluno não ser bem sucedido no exame. (Gallo, 2004, p. 94). 
Gallo questiona se Foucault teria algo a nos dizer sobre a escola enquanto perspectiva de futuro e acena positivamente acerca desse seu questionamento, expectativa da qual compartilho. Afirma que,

Se a escola tem sido, assim como o exército, um dispositivo disciplinador, ela é também um espaço social onde se exercem contrapoderes. Ele mostra-nos que na relação pedagógica o aluno não é um mero paciente, mas é também um agente de poder, o que deve levar-nos a repensar todo o "estrategismo pedagógico" do qual algumas vezes somos vítimas, outras vezes somos sujeitos. (Gallo, 2004, p. 94).

A centralidade da condução da aula já foi papel inquestionável do professor, na lógica de que este ensinava e o aluno aprendia. Os estudos relativos aos processos de aprendizagem, somados aos efeitos da inclusão de pessoas com deficiência nos espaços equivocadamente concebidos como homogêneos, contribuíram para tornar mais explícita a singularidade humana e produzir deslocamentos no conceito de aula, incluindo a avaliação da aprendizagem e o poder que essa prática delega ao professor.

Em discussões sobre práticas avaliativas, como gestora universitária, acompanhei depoimentos referentes a atitudes de docentes que, no primeiro encontro com a turma, já sinalizavam para uma minoria exitosa e uma maioria incapaz de se apropriar de conhecimentos considerados mais relevantes do que outros. Participei de um diálogo com professores de disciplinas nas quais, em determinado período, os percentuais de reprovação foram de $60 \%$ a $80 \%$. O intuito do encontro foi ouvir os docentes desses componentes e, na sequência, dialogar também com os estudantes sobre os resultados constatados e, juntos, pensarmos possibilidades de favorecer a aprendizagem. Observei o discurso da naturalização da reprovação proveniente de um significativo número de professores do campo das ciências exatas. A reprovação, na percepção daquele grupo, acontece porque a educação básica está falida; porque as famílias não definem limites na educação dos filhos e isso repercute na universidade; porque os estudantes "de hoje" não têm interesse nenhum, são adeptos às futilidades e facilidades da vida; porque os estudantes trabalham o dia todo e, cansados, não têm motivação para estudar; porque os estudantes não estão "maduros" etc. Ao finalizarmos a conversa, a sensação é de que nada há por fazer para esse percentual de alunos, que representa a maioria nas turmas das disciplinas em questão. Um dos professores presentes empolgou-se ao relatar suas vivências e dizer que as pessoas aprendem pelo amor (quando atendem ao alerta docente de que precisam dedicar-se a esses componentes difíceis, cujo êxito é para poucos) ou pela dor da reprovação.

Entendo que essa fala está impregnada pelo poder disciplinar que direciona seu foco para a punição. Esse mesmo poder que castiga, controla e pune também recompensa os que obedecem, os que incorporam o princípio do mérito individual. Contudo, constatei que professores que se expressam da forma descrita acerca da educação mudam seu discurso ao referirem-se a estudantes com deficiência, tornando-se mais amenos e solidários. O que a deficiência desperta nesses docentes? 
Faço essas considerações com o intuito de salientar os resultados da pesquisa que fundamentam este texto, pois o contato com o estudante com deficiência é uma possibilidade de muitos professores universitários reavaliarem suas práticas. Alguns, sensibilizados pela deficiência, ficam em conflito diante de um mecanismo de poder docente (a avaliação ou o exame) e a fragilidade que atribuem às pessoas com deficiência. O poder docente se torna difuso e diluído. É o que deixa transparecer o Docente 2, o qual relata ter encontrado muitas dificuldades em relação à avaliação de um estudante cego.

[...] não posso avaliar ele da mesma maneira e é complicado. Porque ao mesmo tempo que eu não posso dar um tratamento privilegiado, exclusivo, eu tenho que incluir ele. [...] Uma das maiores dificuldades foi a avaliação, realmente. [...] eu aplico provas, algumas provas teóricas que são importantes porque a gente também trabalha com conceitos além de práticas. No caso desses alunos eu fiz sempre provas orais, expliquei as questões, mas, mesmo assim, acho que talvez não seja a melhor avaliação, mas também eu desconheço a melhor maneira de avaliar. (Docente 2).

Em diálogo com o Docente 4, questionei se já vivenciou dificuldades em relação à avaliação da aprendizagem dos estudantes em pauta, a exemplo de uma aluna de fotografia que não consegue segurar a câmera em razão da limitação motora. Indaguei se ela foi avaliada de outro jeito, se ele precisou mediar de forma a facilitar a avaliação ou se conseguiu manter os critérios aplicados à turma e verificar a existência ou não das habilidades esperadas.

O que eu não pude exigir, obviamente, foi a pessoa fazer sozinha o exercício da foto. Agora, o domínio da teoria e do controle do aparelho o aluno tinha, mas ele não tinha era o domínio do corpo dele com esse potencial. Então, fui rigorosa igual. O que eu posso dizer é que no caso desses quatro alunos que eu tive, um quase cego, uma aluna com paralisia, duas surdas, a verdade é que esses alunos são mais dẹdicados e apresentam resultados, no geral, melhores do que os outros. E o que eu posso relatar. Então, se eu for rigoroso não serão eles os prejudicados (risos), né, porque outros são os que reprovaram. (Docente 4).

Compreendo que a cultura da competição está tão arraigada nas subjetividades contemporâneas que, quando se quer evidenciar as possibilidades de pessoas com deficiência, são salientadas as lacunas de quem é considerado "normal". "A excelência para todos é um mito, a não ser que se entenda a excelência no sentido kantiano da educação: o de levar cada indivíduo a realizar a máxima perfeição que a sua natureza comporta [...]" (Estrela, 2010, p. 24). Comparar o desempenho de estudantes com e sem deficiência, destacando aspectos lacunares destes e aspectos positivos daqueles, parece amenizar a angústia docente no momento de avaliar e definir a trajetória do estudante no curso, ideia ilustrada na narrativa que segue.

[...] eu nivelo por baixo, eu não nivelo por cima, e mesmo nivelando por baixo você entra em conflito com o aluno, tem problema com o aluno. Eu não passo a mão na cabeça de aluno, mas eu dou oportunidade. Tu não entregou? Então tá, tu vais ficar sem nota, mas tem mais outro exercício 
adiante, a gente vai levando e vai avaliando, no final das contas vê que o A (referência ao estudante com deficiência) fez todos os exercícios e te procurou e os outros não. Mas tu vês que, pela dificuldade que ele tem, muitas vezes ele está nivelado ali, ou ele está um pouco acima dos outros, do que muitos dos outros. (Docente 6).

Alguns entrevistados, a exemplo do Docente 3, relatam que fazem várias tentativas para favorecer a aprendizagem dos estudantes com deficiência ou, pelo menos, evitar a reprovação deles. Trata-se de um princípio pedagógico de promover a aprendizagem? Essa postura é aplicada também aos demais discentes ou os que possuem deficiência recebem um tratamento distinto? O Docente 3 informa em duas passagens da sua narrativa:

[...] ele vai reprovando, reprovando, reprovando, mas de alguma forma, em algum momento ele vai passar, ele vai se formar.

\section{$[\ldots]$}

Inclusive a nossa paciência, dos professores, de todos aqui, já estava no limite. A gente já estava assim: [...] vamos passar porque deu, a nossa parte a gente já fez, e já fez demais. (Docente 3).

Não foram os critérios pedagógicos que definiram a aprovação, mas um "não saber o que fazer" diante de um estudante que não se apropria do conhecimento esperado para a turma. Reprovar outros alunos, os "indisciplinados", parece não ser tão difícil, mas quando o estudante é concebido como frágil, deficiente, o professor entra em conflito e, muitas vezes, opta por um caminho que considera mais fácil: aprovar.

Compreendo que há um vácuo criado entre a inclusão e o papel da universidade, que tem gerado dúvidas por parte dos professores e, muitas vezes, resultado na escolha por caminhos mais fáceis: aprovar e transferir para outros a dura tarefa de informar que, em uma sociedade competitiva e excludente, a inclusão é um grande desafio. A avaliação da aprendizagem é potencializadora desses conflitos, sendo predominantemente classificatória e seletiva, enquanto a inclusão produz subjetividades com vistas à solidariedade e ao ocupar-se com o outro.

A insegurança perante o ato de avaliar é relatada pelo Docente 7:

Eu não me sentia segura para avaliar se ela tinha entendido. Eu fazia a correção com ajuda do intérprete. Sentava com ele, reservava uma, duas horas e pedia: lê para mim o que ela quer dizer, o que está escrito aqui, traduz para mim, e aí eu fazia isso rotineiramente com todas as avaliações. [...] A avaliação no trabalho grupal é complicadíssima, porque atribuir uma nota pelo material escrito, pela produção escrita é para todos, mas existe uma apresentação oral, né? (Docente 7).

O professor prossegue expondo as dificuldades de inserção de duas estudantes surdas nos grupos de trabalho. Relata o cuidado no sentido de manter as estudantes no mesmo grupo, de forma que o intérprete de Língua Brasileira de Sinais (Libras) estivesse concomitantemente com ambas. Acrescenta que buscava inseri-las com alunos que se destacavam na turma, para que pudessem incluí-las no processo. Declara a intencionalidade de 
avaliar com rigor, de não entender a avaliação como facilitação. Porém, afirma direcionar as questões da prova para que o estudante "explique com suas palavras", o que me mobiliza a questionar como atribuir uma nota "com rigor" a questões com o comando descrito. O que é ser rigoroso, nesse contexto? Quais os critérios para avaliar? Para Luckesi, o ato de avaliar significa

[...] investigar a qualidade da realidade e nela intervir, se necessário. Para isso, é preciso conhecê-la através de sua melhor descritiva. Isso implica coleta de dados, que exige instrumentos elaborados segundo as regras da metodologia científica. (Luckesi, 2011, p. 233).

Mesmo concordando com o autor acerca dos critérios necessários à avaliação da aprendizagem estudantil, saliento os efeitos de verdade criados pelos discursos da inclusão (presentes na mídia, nas normativas legais etc.), cuja ambivalência merece ser tensionada, e que reverberam na subjetivação docente diante do estudante com deficiência.

Ainda em relação ao tema avaliação da aprendizagem, o Docente 10 relatou tentativas para envolver duas estudantes surdas nas aulas e na avaliação:

[...] o fato de elas estarem na turma me motivou a começar a trabalhar com os mapas mentais, porque para mim foi uma alternativa ao texto, para que elas não tivessem que produzir textos. Eu adaptei a turma a elas e não elas à turma. [...] mas quando me deparei com o primeiro texto delas, que foi um paper que elas escreveram de cinco páginas, aí que eu me dei conta que talvez a leitura delas não fosse tão fluente como eu imaginava. Que elas escrevem com uma estrutura completamente diferente. (Docente 10).

A narrativa descreve o sofrimento docente diante do desejo de incluir quando há dúvidas do que seja fazer isso, em uma sociedade que quer resultados e exclui quem não os obtém da forma esperada, mas fala em escola e inclusão para todos. Parece instalar-se a suspeita de ineficiência do trabalho do professor.

Prossegue expondo:

No primeiro semestre, o que aconteceu: a avaliação delas não foi tão positiva, e aí eu entro em desespero quando vejo que elas não vão conseguir nota para aprovar. Aí surge aquela situação de: "será que sou eu que estou sendo crítica demais?" Mas ao mesmo tempo você tem que ser justo, porque a avaliação tem que ser a mesma, afinal, é exigência, a delas vai ter que ser a mesma. Então, a proposta não é passar a mão na cabeça, é de que elas têm as mesmas condições. (Docente 10).

O docente narra que conversou com as duas estudantes surdas e elas mesmas admitiram que "estavam devendo" na disciplina, ou seja, apresentavam lacunas no conhecimento, o que os três concluíram tratar-se de "falta de base". Conjuntamente, decidiram pela reprovação.

Assim, a reprovação ficou legitimada. A culpa não é do professor (que relatava esse sentimento ao constatar que não sabia se comunicar com as 
estudantes surdas por desconhecer a língua de sinais) ou das estudantes, mas da "falta de base", termo que circula amplamente nos discursos de professores universitários. Nessa relação, a culpa e o poder ficam difusos, abstratos. Existem culpados nessa relação?

Ao mesmo tempo que revela a sensação de impotência diante de alguns desafios da inclusão, o Docente 1 relata questionar-se acerca do papel da universidade quando o estudante apresenta limitações ou mesmo impossibilidades para desenvolver o perfil de egresso previsto nas Diretrizes Curriculares Nacionais do curso de graduação no qual está matriculado:

[...] a gente vê que há uma deficiência mental, o sujeito está na universidade, mas não dá conta da elaboração de um parágrafo e vai reprovando e reprovando, às vezes avança e reprova, e mais reprova que avança. Ele enxerga, ele escuta, e nós não conseguimos chegar nesse sujeito. (Docente 1).

Saliento a afirmação de Foucault de que a existência de tecnologias de poder, dentre elas a disciplina, permite controlar as condutas. O professor controla a conduta do estudante, mas o professor também é controlado por esferas mais amplas. O poder "[...] não é detido por alguns e despossuído por outros e nem atua somente como uma força que diz 'não'; ao contrário, produz saber, gera discursos e práticas, constitui formas de subjetivação" (Eizirik, 2005, p. 82).

Possa, Naujorks e Rios (2012) nos provocam a pensar sobre a educação especial como uma invenção possibilitada graças ao arranjo de saberes médicos, psicológicos e pedagógicos. Para as autoras, a área de estudo e de atuação nominada educação especial, surgida no final do século 19 e início do século 20:

É a possibilidade de estabelecer uma verdade para conhecer sobre aquele que não era normal, que destoava do conjunto, aquele que se apresentava como enigma a ser "desvelado" e, por fim, curado ou (re)habilitado à vida humana. (Possa; Naujorks; Rios, 2012, p. 471).

Ao fazer referência à avaliação no campo da educação especial, destacam:

O olhar, o exame, a observação, o monitoramento e a experimentação são práticas não discursivas que produzem os discursos de diagnóstico e avaliação, elas têm uma mesma referência, pois têm o poder de estabelecer uma verdade, de inventar uma verdade sobre o sujeito da deficiência e uma forma de atuação do professor da educação especial.

Tornando o indivíduo visível, fragilizado e susceptível a uma circunstância, a uma necessidade educacional, social e cultural, produzse um sujeito pedagógico, com vista a igualá-lo e normalizá-lo. (Possa; Naujorks; Rios, 2012, p. 477).

Beyer (2013), ao escrever sobre inclusão e avaliação, destaca diferentes concepções, conectadas a uma antropologia da pessoa com deficiência, vinculadas a distintos paradigmas, entre eles: a) clínico-médico: a deficiência 
é concebida como uma situação individualizada e o trabalho educacional é definido por orientação terapêutica; b) sistêmico: a deficiência do estudante é avaliada com base nas demandas impostas pelo currículo - "assim, aos alunos cujo insucesso na aprendizagem signifique a impossibilidade na progressão na escola regular, outras alternativas serão oferecidas" (Beyer, 2013, p. 92), a exemplo de escolas especiais; c) sociológico: a deficiência é definida como processo de atribuição social, no qual o olhar do indivíduo é deslocado para o grupo social, ou seja, a reação social produz o agravamento ou amenização da deficiência; e d) crítico-materialista: a deficiência é compreendida como resultado da incapacidade produtiva do indivíduo.

Uma pesquisa sobre alunos com distintas demandas de acessibilidade no ensino superior em dez universidades no estado do Rio Grande do Sul foi publicada por Thoma em 2006, objetivando mapear acadêmicos em situação de inclusão, analisar e problematizar as representações e os discursos sobre os sujeitos incluídos. Thoma identificou diferentes categorias de discursos: clínico-patológicos, pedagógicos, psicológicos, linguísticos, religiosos, estatísticos e jurídicos. Concluiu que as instituições e os docentes necessitam, além de uma postura de aceitação das diferenças, de conhecimentos técnicos para saber trabalhar com estudantes que possuem necessidades educacionais especiais "[...] decorrentes de problemas de aprendizagem, de deficiências mentais, físicas ou sensoriais, de altas habilidades, de síndromes, condutas típicas e outras" (Thoma, 2006, p. 16). Afirmou, também, que as reformas legais não têm sido suficientes para garantir a acessibilidade aos bens e serviços disponíveis na sociedade, pois as representações sociais sobre a deficiência continuam cristalizadas, enfocando aquilo que falta às pessoas deficientes, na lógica da negação do direito de ser diferente.

Somadas aos desafios mencionados pelos pesquisadores, destacados neste texto, no que se refere à inclusão, à acessibilidade, à aprendizagem e à avaliação da aprendizagem, saliento que, nos circuitos universitários, as diferentes facetas da avaliação têm se constituído em uma engrenagem poderosa. Os estudantes são avaliados para ingressar na educação superior (embora essa avaliação esteja facilitada no contexto de disponibilidade de vagas em muitas instituições e cursos); são avaliados também para prosseguir nas diferentes etapas de cada componente curricular e de cada semestre; são avaliados pelo Exame Nacional de Desempenho de Estudantes (Enade), cujo conceito assume o status de vitrine do curso; os professores são avaliados; os cursos são avaliados; as instituições são avaliadas e os resultados frequentemente usados como fatores de ranqueamento em contextos de mercadorização da educação. A avaliação funciona como um dispositivo pedagógico que regula, classifica e nomeia e como uma prática que opera por meio de mecanismos de poder e disciplinamento, ou seja, necessária para colocar em funcionamento a escola e suas práticas pedagógicas. Mas, a avaliação pode, também, representar um diagnóstico que sinaliza possibilidades de intervir nas lacunas da aprendizagem, de olhar para os cursos, para a universidade e seus currículos, de rever conceitos e 
caminhos a trilhar com o intuito de promover a educação inclusiva. Avaliar é necessário.

\section{Considerações finais}

Ao fazer esses tensionamentos sobre a avaliação de estudantes com deficiência na educação superior ou sobre as avaliações externas, não quero negar a importância que atribuo à avaliação que ajuda a olhar "para dentro", a reescrever e executar projetos de forma mais profícua, a olhar para o alcance e fecundidade das ações no campo da educação. Procurei ressaltar a avaliação a partir da experiência da diferença, quando as relações de poder e saber, presentes nas práticas avaliativas, são ressignificadas. A diferença produz efeitos na docência e na estrutura pesada, fixa da escola, provocando fissuras que mobilizam a revisitar a história da universidade com novos olhares, que nos auxiliam a perguntar como, por que e para que avaliamos.

Ao tensionar a avaliação de estudantes com deficiência está implicado o tensionamento do próprio processo de inclusão, porém,

[...] tensionar a inclusão em suas múltiplas facetas não significa defender o retorno à forma como pessoas com deficiência foram predominantemente tratadas até um passado recente: mortas, segregadas, excluídas da sociedade e da vida, visualizadas pelo prisma do exótico, do estranho ou da invisibilidade. Tampouco significa que devemos esperar que algum "iluminado" diga como se faz a verdadeira inclusão, mas provoca a pensar que os caminhos da inclusão e da docência são desenhados no caminhar, no encontro com o novo, com sujeitos diferentes e que exercem a profissão a partir de distintas perspectivas. (Pieczkowski, 2014, p. 189).

Em que pesem os desafios a serem enfrentados no processo de inclusão, comemoro a expansão do acesso de pessoas com deficiência à educação superior e a ocupação dos seus espaços nesse cenário. As pessoas com deficiência existiram e existem. Saíram dos muros dos hospícios, dos mosteiros, da Nave dos Loucos (Narrenschiff), mencionada por Foucault. Fico provocada a saber como acontece a inserção desses egressos em uma sociedade que é pouco generosa, que, como afirma Gadelha (2009. p. 81), busca indivíduos "proativos, inovadores, inventivos, flexíveis, com senso de oportunidade, com notável capacidade de provocar mudanças, etc.". Considero relevante o desenvolvimento de pesquisas que acompanhem esses estudantes graduados, o seu desempenho no exercício profissional e o seu reconhecimento social.

Alguns docentes entrevistados identificam uma inclusão ambivalente, com fragilidades e até impossibilidades. A ambivalência da inclusão se manifesta no fato de a escola inclusiva sinalizar para princípios como temporalidade distinta, solidariedade, respeito à diferença, porém, organizar-se predominantemente com base em princípios da modernidade sólida, com tempos e espaços fixos para todos. Ao mesmo tempo que o apelo do Estado é para instituições e professores inclusivos, as universidades 
são avaliadas por indicadores padronizados, com foco nos resultados. Na conjuntura atual, a avaliação e a regulação assumem grande prestígio, e as instituições são comparadas e estimuladas a competir entre si na busca por melhores colocações. Qual o lugar, nesse cenário, das pessoas com deficiência intelectual, por exemplo, que também estão frequentando cursos superiores, com acentuadas lacunas em habilidades básicas como leitura, escrita, cálculo, interpretação etc.? Não é o caso de problematizar os próprios currículos dos cursos superiores se desejamos incluir todos os estudantes?

Para Veiga-Neto e Lopes (2011, p. 129-130),

O uso alargado da palavra inclusão, além de banalizar o conceito e o sentido ético que pode ser dado a ela, também reduz o princípio universal das condições de igualdade "para todos" a uma simples introdução "de todos" num mesmo espaço físico.

Os autores chamam atenção para práticas de incluir para excluir, o que resulta em uma inclusão excludente.

Este artigo não teve como intuito apresentar modelos, técnicas ou instrumentos de avaliação. Mas, essencialmente, destacar os conflitos docentes diante de concepções predominantes de avaliação, como mensuração e classificação, e o apelo ao acolhimento fomentado pelos movimentos da educação inclusiva.

O estudo instiga reflexões acerca da inclusão, da democratização da educação superior e do conhecimento, do encontro com "o outro" e dos efeitos desse encontro no jeito de ser docente e conceber a docência. Esse encontro parece despertar no professor a consciência de que ele também possui fragilidades, que muitas vezes precisa aprender antes de ensinar, e, dessa forma, relativiza seu poder de aprovação/reprovação ou de classificação dos estudantes. Lara et al. (2010, p. 5) salientam que

O vínculo que se estabelece entre o aluno e seu professor incide na própria construção subjetiva de ambos, mas também no que se refere à trama que se estabelece entre as questões da ordem da subjetividade e da objetividade nos processos de aprender e de ensinar.

Concordo com Anastasiou (2004) quando afirma que a profissão docente, por trabalhar com a mudança e a construção, é marcada por imprevisibilidade, singularidade, incerteza, novidade, dilema, conflito e instabilidade. Em razão disso, Isaia e Bolzan (2009, p. 165) evidenciam que

[...] formação e desenvolvimento profissional entrelaçam-se em um intrincado processo, a partir do qual a professoralidade vai se construindo pouco a pouco. O saber-saber e o saber-fazer da profissão não são dados a priori, mas arduamente conquistados ao longo da carreira docente.

Reconhecer a diferença, o "outro" como sujeito pleno, ajuda-nos a ser professores melhores e a avaliar nossas práticas ao mesmo tempo que avaliamos nossos estudantes. 


\section{Referências bibliográficas}

AMARAL, L. A. Pensar a diferença/deficiência. Brasília: Corde, 1994.

ANASTASIOU, L. G. C. Docência no ensino superior e profissionalização. In: SEMINÁRIO DE PESQUISA EM EDUCAÇÃO DA REGIÃO SUL

(ANPEDSUL), 4., 2004, Curitiba. Anais. . . Curitiba: PUCPR, 2004. 1 CDROM.

BEYER, H. O. Inclusão e avaliação na escola: de alunos com necessidades educacionais especiais. 4. ed. Porto Alegre: Mediação, 2013.

BRASIL. Decreto n ${ }^{0} 6.949$, de 25 de agosto de 2009. Promulga a Convenção Internacional sobre os Direitos das Pessoas com Deficiência e seu Protocolo Facultativo, assinados em Nova York, em 30 de março de 2007. Diário Oficial da União, Brasília, DF, 26 ago. 2009. Seção 1, p. 3. Disponível em: <http://legislacao.planalto.gov.br/legisla/legislacao.nsf/ Viw_Identificacao/DEC\%206.949-2009?OpenDocument>. Acesso em: fev. 2015.

BRASIL. Lei $\mathrm{n}^{\circ}$ 13.146, de 6 de julho de 2015. Institui a Lei Brasileira de Inclusão da Pessoa com Deficiência (Estatuto da Pessoa com Deficiência). Diário Oficial da União, Brasília, DF, 7 jul. 2015. Seção 1, p. 2. Disponível em: <http://www.planalto.gov.br/ccivil_03/_Ato2015-2018/2015/Lei/ L13146.htm> Acesso em: 19 jul. 2015.

BRASIL. Instituto Nacional de Estudos e Pesquisas Educacionais Anísio Teixeira (Inep). Sinopses estatísticas da educação superior - graduação: censo da educação superior de 2013. 2015. Disponível em: <http:// portal.inep.gov.br/superior-censosuperior-sinopse>. Acesso em: 24 out. 2015.

EIZIRIK, M. F. Michel Foucault: um pensador do presente. 2. ed. rev. ampl. Ijuí: Unijuí, 2005.

ESTRELA, M. T. Ética e pedagogia no ensino superior. In: LEITE, C. (Org.). Sentidos da pedagogia no ensino superior. Porto: CIIE/Livpsic, 2010. p. 11-28. (Coleção Ciências da Educação, 7)

FOUCAULT, M. Vigiar e punir: nascimento da prisão. Tradução de Raquel Ramalhete. 20. ed. Petrópolis: Vozes, 1999.

FOUCAULT, M. História da sexualidade I: a vontade de saber. 16. ed. Rio de Janeiro: Graal, 2005. 
FOUCAULT, M. As palavras e as coisas: uma arqueologia das ciências humanas. Tradução de Salma Tannus Muchail. 9. ed. São Paulo: Martins Fontes, 2007. (Coleção Tópicos).

GADELHA, S. S. Governamentalidade neoliberal e teoria do capital humano e empreendedorismo. Educação \& Realidade, Porto Alegre, v. 34, n. 2, p. 171-186, maio/ago. 2009.

GALLO, S. Repensar a educação: Foucault. Educação \& Realidade, Porto Alegre, v. 29, n. 1, p. 79-97, jan./jun. 2004.

\section{INSTITUTO BRASILEIRO DE GEOGRAFIA E ESTATÍSTICA (IBGE).}

Censo demográfico 2010: características gerais da população, religião e pessoas com deficiência. Rio de Janeiro, 2012. Disponível em: <http:// biblioteca.ibge.gov.br/visualizacao/periodicos/94/cd_2010_religiao_ deficiencia.pdf $>$. Acesso em: 14 abr. 2014.

ISAIA, S. M. A.; BOLZAN, D. P. V. Construção da profissão docente: possibilidades e desafios para a formação. In: ISAIA, S. M. A.; BOLZAN, D. P. V.; MACIEL, A. M. R. (Orgs.). Pedagogia universitária: tecendo redes sobre a educação superior. Santa Maria: UFSM, 2009. p. 163-176.

LARA, A. T. S. et al. Inclusão de alunos com deficiências: uma discussão com professores da PUCRS. In: FREITAS, A. L. S. et al. (Orgs.).

Capacitação docente: um movimento que se faz compromisso. Porto Alegre: EDIPUCRS, 2010. p. 47-60. Disponível em: <http://www.pucrs. br/edipucrs/capacitacaodocente.pdf >. Acesso em: 11 jan. 2013.

LUCKESI, C. Avaliação da aprendizagem escolar: estudos e proposições. 22. ed. São Paulo: Cortez, 2011.

PIECZKOWSKI, T. M. Z. Inclusão de estudantes com deficiência na educação superior: efeitos na docência universitária. 2014. 208 f. Tese (Doutorado em Educação) - Centro de Educação, Universidade Federal de Santa Maria, Santa Maria, 2014.

POSSA, L. B.; NAUJORKS, M. I.; RIOS, G. M. S. Matizes do discurso sobre avaliação na formação de professores da educação especial.

Educação Especial, Santa Maria, v. 25, n. 44, p. 465-489, set./dez. 2012.

SALES, S. R. Etnografia + análise do discurso: articulações metodológicas para pesquisar em Educação. In: MEYER, D. E; PARAÍSO, M. A. (Orgs.). Metodologias de pesquisas pós-críticas em educação. Belo Horizonte: Mazza, 2012. p. 111-132.

THOMA, A. S. A inclusão no ensino superior: "- ninguém foi preparado para trabalhar com esses alunos (...) isso exige certamente uma 
política especial...". In: REUNIÃO ANUAL DA ANPED, 29., 2006,

Caxambu. Anais. . . Caxambu: Anped, out. 2006. Disponível em:

$<$ http://29reuniao.anped.org.br/trabalhos/trabalho/GT15-2552--Int.

pdf $>$. Acesso em: 16 nov. 2011.

VEIGA-NETO, A.; LOPES, M. C. Inclusão, exclusão, in/exclusão. Verve, São Paulo, n. 20, p. 121-135, 2011.

Recebido em 25 de agosto de 2015.

Solicitação de correções em 22 de janeiro de 2016.

Aprovado em 24 de agosto de 2016. 